\title{
Sistem Aplikasi Peminjaman Kendaraan Bermotor PT Trans Mitra Nusantara
}

\author{
Riskal Septiawan Pratama1, Agus Kodir Arifin², Anggun Citra Dini Dwi Puspitasari ${ }^{3}$ \\ ${ }^{1,2,3}$ Program Studi Informatika, Universitas Indraprasta PGRI, Pasar Rebo, Jakarta Timur, Indonesia \\ e-mail: ${ }^{1}$ riskalseptiawan@gmail.com, ${ }^{2}$ agus.arifin@gmail.com, ${ }^{3}$ anggun_citra@gmail.com \\ Submitted Date: December $11^{\text {th }}, 2019$ \\ Revised Date: February $14^{\text {th }}, 2020$ \\ Reviewed Date: December 30 ${ }^{\text {th }}, 2019$ \\ Accepted Date: April 29, 2020
}

\begin{abstract}
A vehicle loan system must be able to carry out its operational activities in an effective and efficient manner. PT TRANS MITRA NUSANTARA is still using the manual method in the loan data collection process, for this reason, a computerized system has been proposed, the Vehicle Loan Application System. The analysis used utilizes the Qualitative Method as a research method carried out by conducting observations, interviews, to find data, obtain, collect or record data that can be used for purposes, and factors related to the subject matter so that a truth will be obtained from the data which is obtained. The results obtained can be concluded that the vehicle lending application system can assist employees in processing input data, and the process of vehicle lending transactions and accelerate the process of making vehicle lending reports.
\end{abstract}

Keywords: System, Application, Vehicle Loan.

\section{Abstrak}

Suatu sistem peminjaman kendaraan harus mampu melaksanakan kegiatan operasionalnya dengan cara yang efektif dan efisien. PT TRANS MITRA NUSANTARA masih menggunakan cara manual dalam proses pendataan peminjaman, untuk itu telah diusulkan sistem yang terkomputerisasi yaitu Sistem Aplikasi Peminjaman Kendaraan. Analisis yang digunakan memanfaatkan Metode Kualitatif sebagai metode penelitian yang dilaksanakan dengan mengadakan observasi, wawancara, untuk mencari data, memperoleh, mengumpulkan atau mencatat data yang dapat digunakan untuk keperluan, dan faktor-faktor yang berhubungan dengan pokok permasalahan sehingga akan didapat suatu kebenaran atas data yang diperoleh. Hasil penelitian yang diperoleh dapat disimpulkan bahwa sistem aplikasi peminjaman kendaraan ini dapat membantu karyawan dalam pengolahan masukan data, dan proses transaksi peminjaman kendaraan serta mempercepat proses pembuatan laporan peminjaman kendaraan.

Kata Kunci : Sistem, Aplikasi, Peminjaman Kendaraan.

\section{Pendahuluan}

Perkembangan teknologi dari masa ke masa mengalami kemajuan yang sangat signifikan. Berbagai macam aktivitas manusia sudah banyak yang bersentuhan dengan komputer, terutama kegiatan untuk pengumpulan dan pengelolaan data, serta keinginan untuk mendapatkan data atau informasi dengan mudah dan cepat. Perusahaan mempunyai keterkaitan dengan teknologi komputer, bertujuan untuk mempermudah dalam usaha yang nantinya dalam proses transaksi akan jaduh lebih cepat dan tepat, Sehingga perusahaan tidak lagi menggunakan media kwitansi. jadi, komputer pada saat ini telah dijadikan sebagai alat prasarana yang sangat penting di dalam sebuah usaha. Penggunaan komputer dalam usaha bukan merupakan hal yang baru karena komputer dapat di jadikan sebagai alat untuk melakukan pengolahan data, pembuatan laporan, dan penyimpanan data yang menghasilkan suatu informasi yang cepat, tepat, dan akurat. Akan tetapi, masih ada perusahaan yang masih menggunakan cara manual dalam mengolah data seperti PT TRANS MITRA NUSANTARA. 
Perancangan sistem aplikasi peminjaman kendaraan di PT TRANS MITRA NUSANTARA berbasis java yaitu untuk mempercepat dan mempermudah proses penyimpanan data dan peminjaman kendaraan, mempermudah dalam pembuatan laporan yang efisiensi.

Penelitian ini dilakukan di PT TRANS MITRA NUSANTARA yang membutuhkan sistem aplikasi peminjaman kendaraan yang terkomputerisasi, maka dibuatlah aplikasi berbasis komputer dengan menggunakan Java dengan maksud memberikan kemudahan bagi perusahaan ini dalam pengolahan data peminjaman kendaraan dengan baik. metode pengumpulan data yang digunakan dalam pembuatan aplikasi ini adalah kunjungan, wawancara, dan studi pustaka.

Data-data yang telah diproleh tersebut kemudian di ujicobakan melalui perancangan aplikasi peminjaman kendaraan berbasis java.

Kamus data merupakan suatu elemen atau simbol-simbol yang digunakan untuk membantu dalam mengidentifikasi setiap data didalam sistem. (Kristanto, 2018). Suatu sistem dapat diklasifikasikan sebagai abstrak, abstrak adalah suatu gambaran ide yang tidak terwujud secara jelas. Sistem fisik merupakan sistem yang ada secara jelas dan nyata. (Jogiyanto, 2017). Sistem merupakan suatu jaringan prosedur yang dibuat secara tersusun untuk melaksanakan kegiatan pokok perusahaan. (Mulyadi, 2016). Jasa adalah sesuatu yang dapat ditawarkan oleh satu pihak kepada pihak lain, yang bentuknya tidak terwujud. (Kotler, 2012).

Rekaya Perangkat Lunak adalah istilah untuk data yang telah terformat dan tersimpan secara komputerisasi. (Nugroho, 2014). Sebuah sistem masing-masing mempunyai sifat-sifat berbeda, yaitu mempunyai kumpulan komponen, batas, lingkungan luar, penghubung, masukan, keluaran, pengolah, dan sasaran atau tujuan. (Hutahaean, 2015). Entity Relationship Diagram merupakan suatu bentuk data yang dikembangkan berdasarkan objek. (Utama, 2011). Perangkat lunak aplikasi adalah suatu perangkat lunak komputer yang kemampuannya untuk melakukan suatu perintah yang diinginkan user. (Amras Mauluddin, 2011). MySQL termasuk jenis database server yang sangat amat dikenal oleh para programer. (Renatha, Satoto, \& Nurhayati, 2015). normalisasi suatu teknik dengan pendekatan yang digunakan dalam membantu mengidentifikasikan sebuah hubungan. (Fuad, 2015).

\section{Metode Penelitian}

Peneliti menggunakan cara metode penelitian kualitatif. Yaitu penelitian tentang riset yang bersifat deskriptif dan menggunakan analisis. metode pengumpulan data dilakukan selama 2 bulan yaitu bulan mei hingga juni yang digunakan dengan 2 cara data primer dan skunder. Data primer dilakukan dengan melakukan wawancara antara dua orang untuk memperoleh informasi dengan cara observasi langsung di PT TRANS MITRA NUSANTARA. Pengumpulan data skunder yaitu mempelajari dan mengamati beberapa dokumen tentang mengenai sistem administrasi, mengadakan pengamatan untuk memahami sistem berjalan terutama pada proses peminjaman kendaraan.

Langkah-langkah pengembangan sistem dalam penyusunan tugas akhir sebagai berikut:
a. Analisis Kebutuhan
b. Perancangan Sistem
c. Implementasi Sistem dan Evaluasi sistem
d. Pengujian Sistem.

\section{Hasil dan Pembahasan}

PT TRANS MITRA NUSANTARA termasuk salah satu perusahaan yang belum memiliki sistem aplikasi pengolahan data peminjaman berbasis komputerisasi, ada masalah yang dirasakan oleh perusahaan yaitu masih dilakukan pendataan secara manual dan belum terkomputerisasi sehingga menyusahkan karyawan ketika akan melakukan pencarian data ataupun pengarsipan data. Pencatatan data peminjaman yang berjalan belum maksimal karena penggunaan kertas sebagai sarana pencatatan peminjaman kendaraan. Dalam proses peminjaman kendaraan masih menggunakan pencatatan buku besar dan mencari satu persatu sehingga karyawan merasa kesulitan dalam mencari data.

Berdasarkan analisis sistem yang sedang berjalan saat ini penyusun melihat adanya kekurangan, maka dibuat aturan yang akan memberikan beberapa saran sebagai alternatif penyelesaian masalah yaitu dengan membuat sebuah aplikasi pengolahan data peminjaman kendaraan dengan menggunakan bahasa pemrograman java dan menyimpan data-data pada media database.

Dengan adanya aplikasi ini diharapkan mampu mmeberikan kontribusi yang positif bagi 
kemajuan dalam pengolahan data-data agenda peminjaman kendaraan dan proses pencarian data tidak lagi membutuhkan waktu yang lama. Aturan tersebut meliputi melakukan pendataan pada konsumen, setelah itu konsumen akan mendapatkan nomor urutan konsumen. Selanjutnya setiap peminjaman kendaraan akan dilakukan pendataan agar mendapatkan nomor bukti konsumen dan peminjaman kendaraan.
Kemudian pada saat pengembalian kendaraan, akan dilakukan pendataan apakah sesuai dengan awal peminjaman atau tidak. Setelah itu laporan dibuat untuk mengetahui data konsumen yang melakukan peminjaman kendaraan setiap harinya dan melihat jumlah yang harus dibayar. Setelah itu diserahkan pada pimpinan PT TRANS MITRA NUSANTARA.

\section{Diagram Alir Data (DAD) Sistem yang Berjalan}

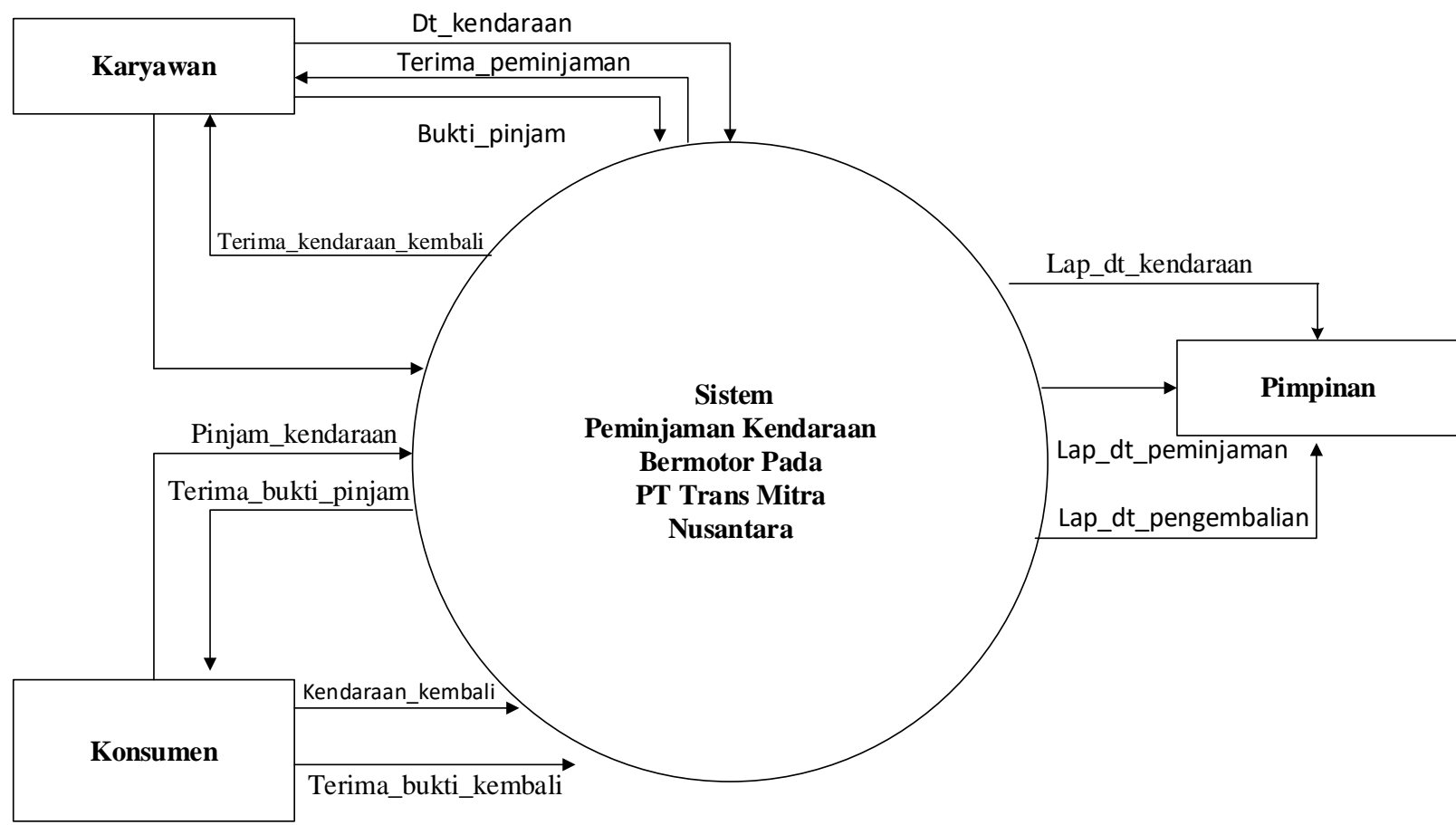

Gambar 1. Diagram Konteks Sistem Berjalan

Dari hasil penelitian penulis dapat mengambil kesimpulan bahwa:

a. Perusahaan ini termasuk salah satu perusahaan yang belum memiliki sistem aplikasi pengolahan data berbasis komputerisasi.

b. Pencatatan data peminjaman saat ini belum sempurna karena tidak tersedianya sistem aplikasi sebagai sarana pencatatan peminjaman kendaraan.

c. Pada laporan peminjaman yang masih dilakukan secara manual dengan menggunakan berkas sehingga menyulitkan karyawan ketika akan melakukan pencarian data ataupun pengarsipan data.

\section{Solusi Penyelesaian Masalah}

Untuk penyelesaian masalah maka diusulkan beberapa solusi:

a. Membuat sistem aplikasi pengolahan data yang dapat membantu kinerja karyawan dalam pengolahan data peminjaman.

b. Perancangan database sistem untuk media penyimpanan data sehingga dapat mengantisipasi adanya kehilangan data.

c. Pada pencarian dan pembuatan laporan sudah tertata dengan baik, sehingga karyawan tidak lagi membutuhkan waktu lama.

d. Dengan adanya aplikasi ini diharapkan mampu memberikan kontribusi yang 
positif bagi kemajuan dalam pengolahan data-data agenda peminjaman kendaraan.

\section{Diagram Alir Data (DAD) yang Diusulkan}

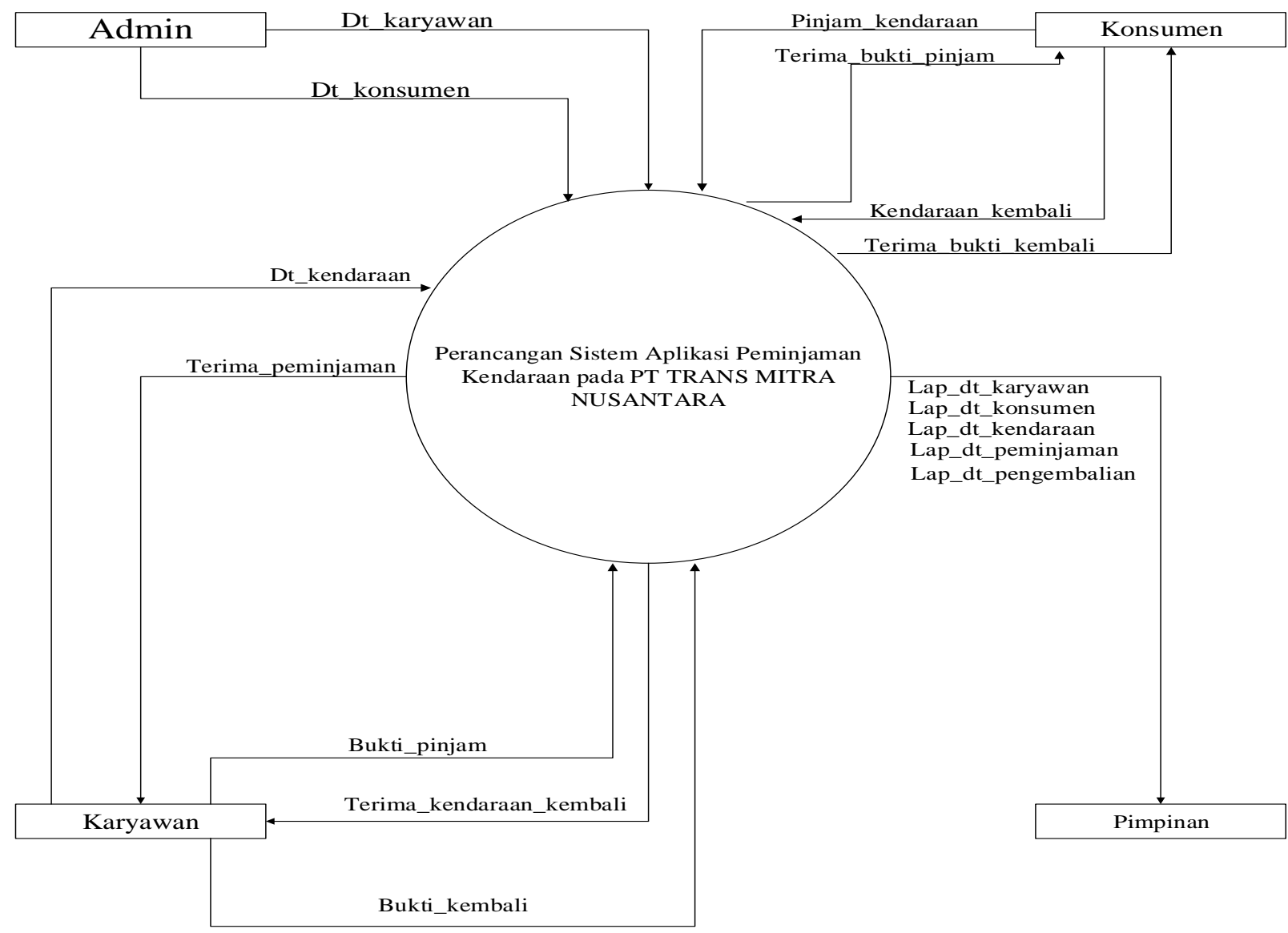

Gambar 2. Diagram Konteks Sistem Diusulkan

Selanjutnya adalah rancangan basis data sistem yang diusulkan. berikut gambar ERD yang diusulkan

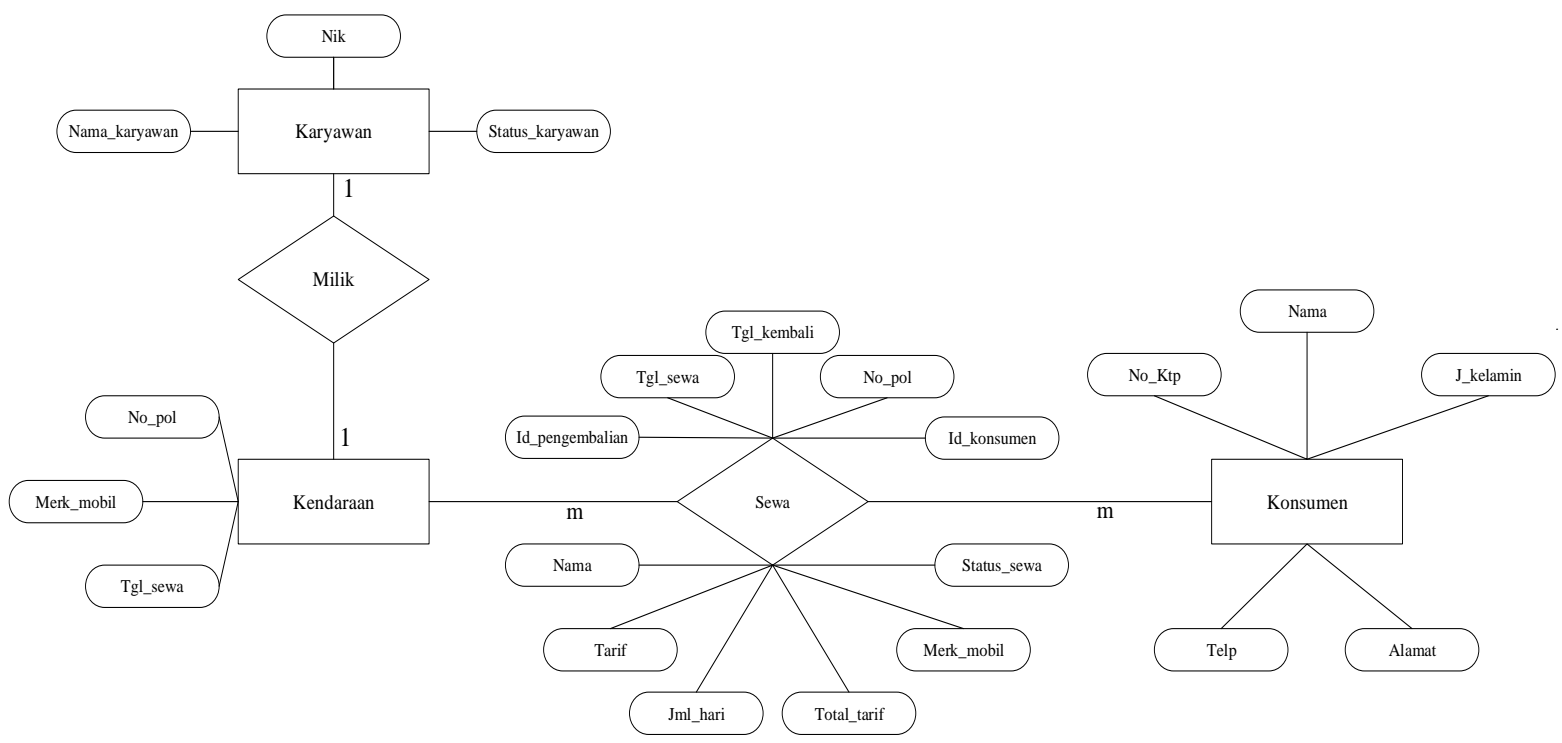




\section{Gambar 3. Entity Relation Diagram}

Selanjutnya yaitu tampilan menu login yang diisi oleh karyawan. Berikut tampilan gambar form login dengan memasukan Username and password.

\begin{tabular}{|c|c|}
\hline LOGIN & 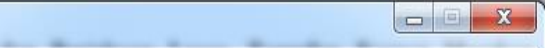 \\
\hline \multicolumn{2}{|c|}{ 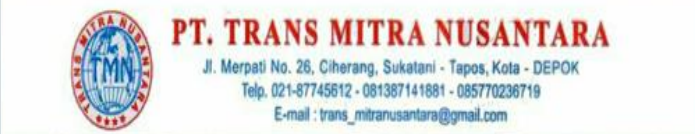 } \\
\hline \multicolumn{2}{|r|}{ LOGIN ADMIN } \\
\hline USERNAME & LOGIN \\
\hline PASSWORD & EXIT \\
\hline
\end{tabular}

Gambar 4. Tampilan Form Login

Setelah user memasukan Username dan Password akan muncul beberapa tampilan menu utama yang siap menjalankan perintah user tersebut.

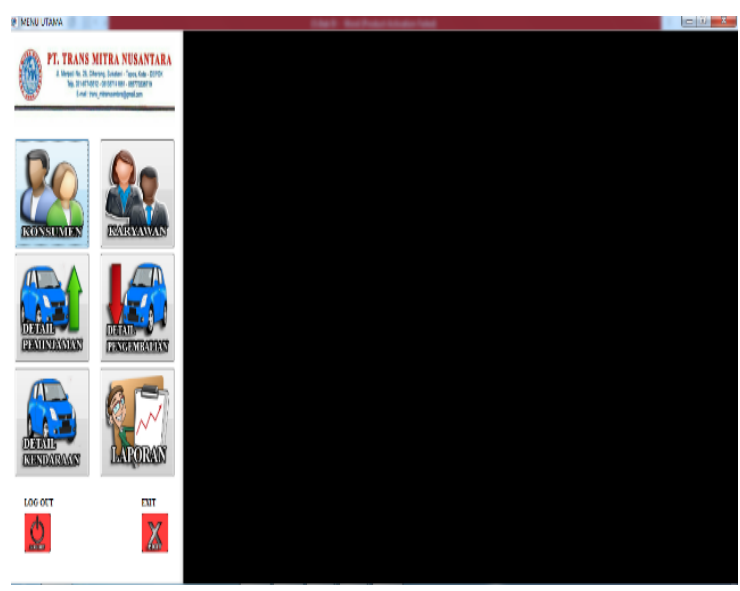

Gambar 5. Tampilan Form Menu Utama

Pertama, karyawan memasukkan identitas karyawan, maka akan keluar tampilan form memasukkan data karyawan seperti berikut.

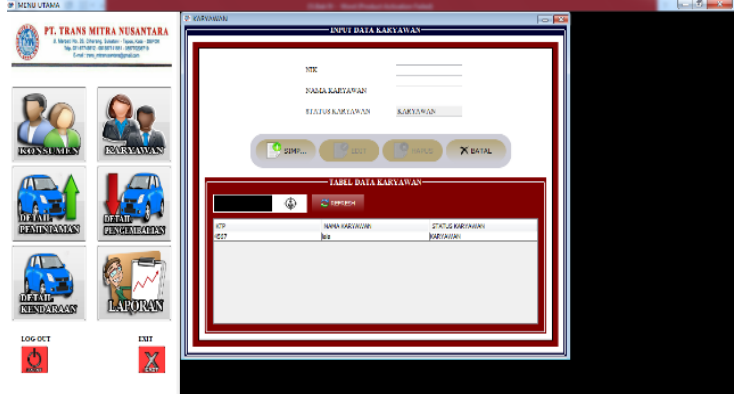

Gambar 6. Tampilan Form Data Karyawan

Kedua, karyawan memasukkan konsumen yang ingin meminjam kendaraan. Berikut tampilan form data konsumen.

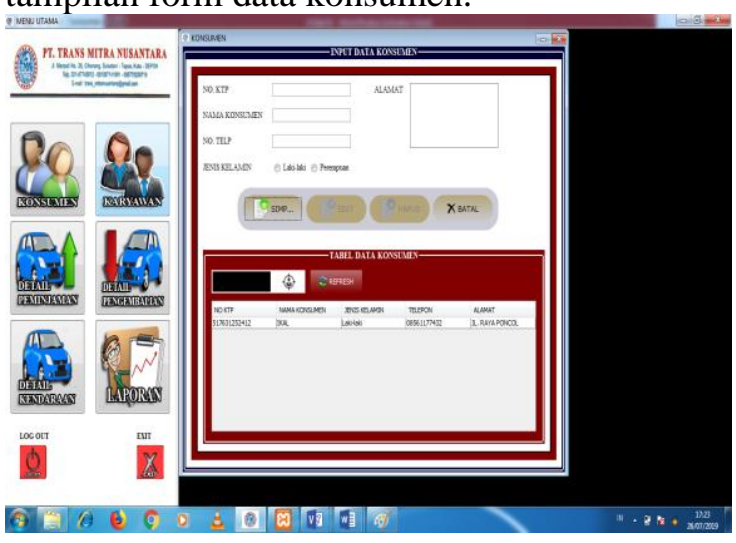

\section{Gambar 7. Tampilan Form Data Konsumen}

Ketiga, karyawan memasukkan data kendaraan pada form data kendaraan untuk memasukkan data kendaraan yang ada seperti berikut.

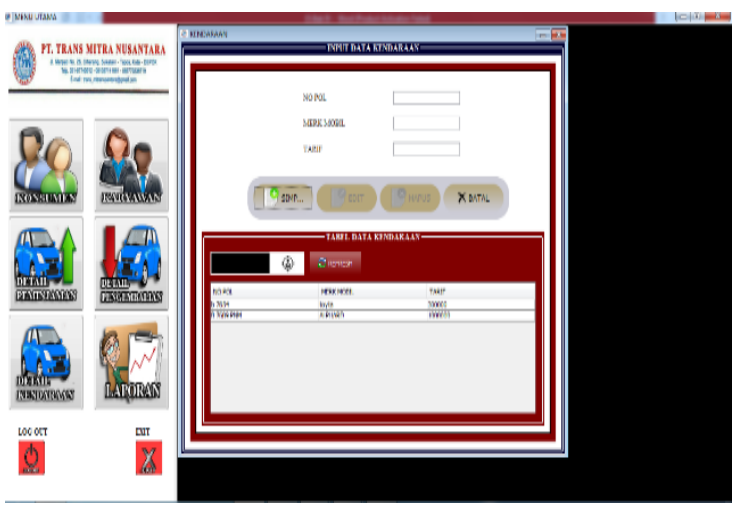

Gambar 8. Tampilan Form Data Kendaraan

Keempat, karyawan memasukkan data peminjaman untuk selanjutnya di cetak untuk 
bukti jika kendaraan yang ada telah di pinjamkan oleh konsumen.

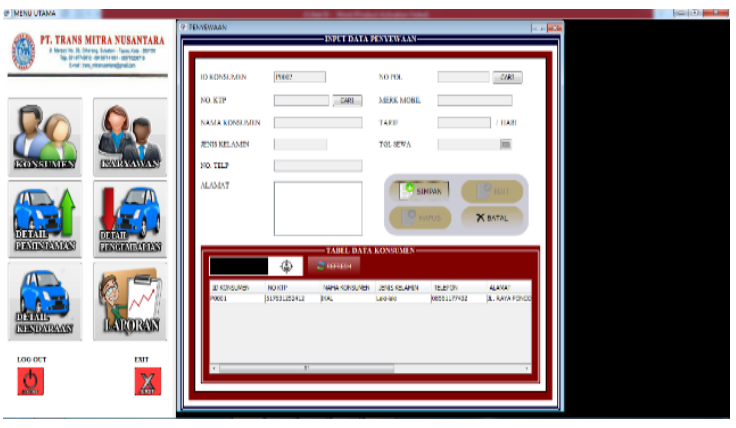

\section{Gambar 9. Tampilan Form Data Peminjaman}

Kelima, karyawan memasukkan kendaraan yang telah dikembalikan oleh konsumen. Berikut tampilan form data pengembalian kendaraan.

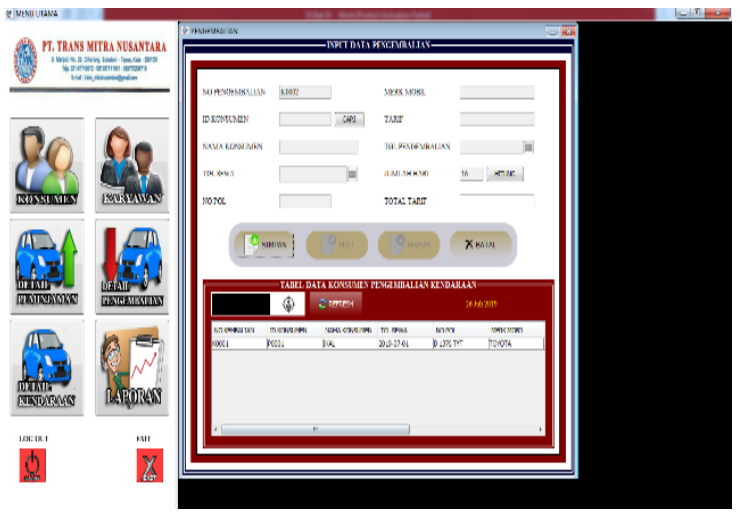

\section{Gambar 10. Tampilan Form Data Pengembalian}

Setelah semua data dimasukkan, maka tampilan laporan data karyawan akan seperti pada tampilan dibawah ini yang akan ditanda tangani oleh HRD.

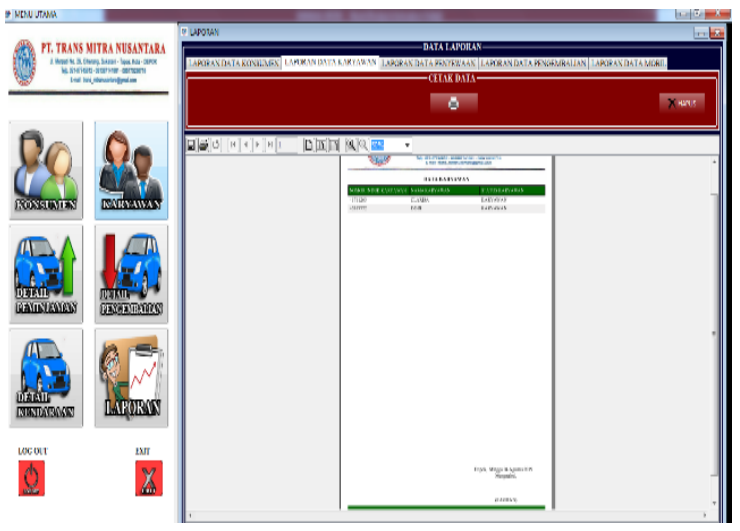

\section{Gambar 11. Tampilan Form Data Laporan Karyawan}

Tampilan laporan data konsumen juga akan menyesuaikan dengan pendataan konsumen yang telah dilayani dan akan ditanda tangani oleh HRD. Berikut tampilan data konsumen.

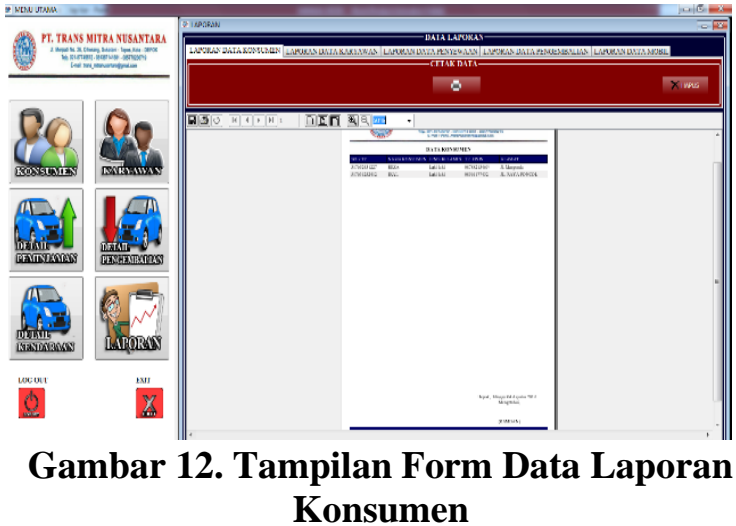

Selanjutnya tampilan laporan data kendaraan juga menyesuaikan, yang nantinya akan ditanda tangani oleh HRD. Berikut tampilannya.

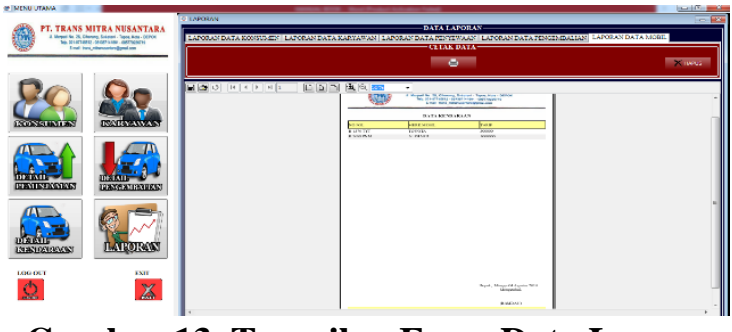

Gambar 13. Tampilan Form Data Laporan Kendaraan

Setelah itu, tampilan laporan data peminjaman akan menyesuaikan data yang telah dimasukkan pada form-form sebelumnya dan nantinya akan ditanda tangani oleh HRD. ini tampilannya.

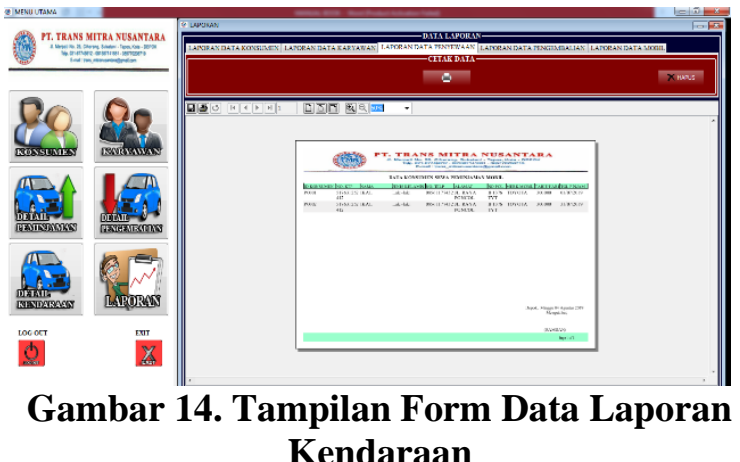


Setelah laporan data peminjaman, ada tampilan data laporan pengembalian yang menyesuaikan dengan data yang ada dan nantinya akan ditanda tangani oleh HRD. Berikut tampilannya.

\section{Simpulan}

Berdasarkan hasil pembahasan yang telah diuraikan pada bab-bab sebelumnya dan menyesuaikan dari rumusan masalah yang ada, maka kesimpulan yang diperoleh penulis adalah sebagai berikut:

1. Sudah tersedianya aplikasi yang menangani peminjaman kendaraan pada PT TRANS MITRA NUSANTARA. Sehingga dapat mempermudah karyawan dalam melakukan pendataan yang menangani peminjaman kendaraan.

2. Proses administrasi pada PT TRANS MITRA NUSANTARA telah menggunakan media yang terkomputerisasi sehingga mempermudah pegawai dalam melakukan pengelolaan administrasi.

3. Pada proses pembuatan laporan dan pencarian data pada PT TRANS MITRA NUSANTARA telah terkomputerisasi sehingga hasil laporan atau output lebih akurat.

\section{Saran}

Dalam perancangan sistem informasi pelayanan medis ini masih banyak hal yang dapat dikembangkan, seperti:

1. Dalam menggunakan sistem yang terkomputerisasi ini diharapkan selalu melakukan backup data (laporan), sehingga apabila terjadi hal-hal yang tidak diinginkan, seperti harddisk rusak maka data masih akan tetap aman tersimpan.

2. Untuk meningkatkan pelayanan yang akan diaplikasikan sebaiknya didukung oleh hardware yang lebih memadai.

\section{Referensi}

Amras Mauluddin, Sk. (2011). Aplikasi Web Browser Menggunakan Metode Url (Universal Resource Locator) Pada Sistem Operasi Window. Jurnal INFORMASI.

Fuad, M. (2015). Perancangan Sistem Informasi Simpan Pinjam Pada Koperasi " KOPITAMA" Depok. UG Jurnal.

Hutahaean. (2015). Karakterisrik Sistem. KARAKTERISTIK SISTEM.

Jogiyanto. (2017). Konsep Dasar Sistem Informasi. Konsep Dasar Sistem Informasi.

Kotler, P. (2012). Marketing management/Philip
Kotler, Kevin Lane Keller. In Marketing management.

Kristanto, A. (2018). Perancangan Sistem Informasi dan Aplikasinya (Edisi Revisi). In Gava Media. https://doi.org/10.1017/CBO9781107415324.0 04

Mulyadi. (2016). Pengertian sistem menurut mulyadi. In Sistem Akuntansi.

Nugroho, A. (2014). Rekayasa Perangkat Lunak Menggunakan UML \& Java. In Rekayasa Perangkat Lunak Menggunakan UML \& Java.

Renatha, F. A., Satoto, K. I., \& Nurhayati, O. D. (2015). Perancangan dan Pengembangan Sistem Informasi Perpustakaan Berbasis Web (Studi Kasus Jurusan Sistem Komputer). Jurnal Teknologi Dan Sistem Komputer. https://doi.org/10.14710/jtsiskom.3.3.2015.343353

Utama, Y. (2011). Sistem Informasi Berbasis Web Jurusan Sistem Informasi Fakultas Ilmu Komputer Universitas Sriwijaya. Jurnal Sistem Informasi (JSI). 